\title{
UMA CONTRIBUIÇÃO PARA A DISCUSSÃO SOBRE AS IMAGENS PSÍQUICAS NO CONTEXTO DA PSICOLOGIA ANALÍTICA ${ }^{1}$
}

\author{
Paulo Afrânio Sant'Anna ${ }^{2}$ \\ Faculdade de Psicologia da Universidade Presbiteriana Mackenzie
}

A discussão sobre a natureza das imagens psíquicas ocorre desde os primórdios da Psicologia. Nas últimas décadas, o tema vem ganhando destaque em todas as abordagens, notadamente em modalidades clínicas que se apóiam predominantemente no discurso imagético. Para a Psicologia Analítica, a questão da imagem tem sido tema de diversas discussões, destacando-se três direcionamentos teórico-práticos clássico, desenvolvimentista e arquetípico -, que vão determinar diferentes perspectivas sobre a questão. Observa-se uma tendência em abordar a imagem a partir de sua própria fenomenologia, em detrimento de sua interpretação e, apesar da importância das imagens para o contexto clínico, o tema está praticamente ausente dos programas de graduação em Psicologia e da própria estruturação das teorias psicológicas. Nesse sentido, algumas propostas são discutidas a título de possibilidades de aprendizado $e$ de teorização no campo da imagem.Como a relação dialética entre teoria e prática é necessária para que a teoria permaneça atualizada e vitalmente ligada à realidade sociocultural contemporânea, por meio de dados obtidos em entrevistas com psicoterapeutas brasileiros, buscou-se identificar contribuições para a discussão sobre as imagens no contexto clínico.

Descritores: Imagem. Psicoterapia. Psicologia junguiana. Formação do psicólogo.

1 Trabalho derivado da tese de doutorado As imagens no contexto clínico de abordagem junguiana: uma interlocução entre teoria e prática, apresentada ao IPUSP, em 2001, com apoio financeiro da Capes.

2 Rua Henrique Botticini, 44 - Butantã, São Paulo, SP - CEP 05587-020 - Tel. (011) 37264722 e 9794 6747. Endereço eletrônico: pauloasantanna@terra.com.br 


\section{Notas introdutórias}

Há pouco mais de um século de seu nascimento, a Psicologia deparase com a necessidade de rever em profundidade muito de seus pressupostos teóricos e de suas práticas, com o intuito de recuperar sua vitalidade inicial.

Nos primórdios do século XX, a Psicologia e a psicoterapia eram campos novos, impregnados de mistério e desafios, o que deu origem a movimentos teóricos dinâmicos e criativos. No entanto, à medida que esses movimentos foram se sedimentando em escolas e teorias psicológicas, suas idéias perderam, gradualmente, a vitalidade original a favor da unidade e pureza conceituais. O resultado desse processo parece ter sido a cristalização das visões sobre o fenômeno psíquico.

Na Psicologia Analítica, a preocupação excessiva com o estilo ou o método junguiano tem provocado um distanciamento de questões importantes para a Psicologia contemporânea, sobretudo para as que dizem respeito a uma prática clínica mais próxima da realidade sociocultural atual. Em face do enorme avanço tecnológico, das profundas transformações sociais, políticas e culturais e da grande variedade de fenômenos psíquicos, que se apresentam de forma epidêmica, a Psicologia Analítica parece ter como desafio encontrar meios que favoreçam, de modo mais efetivo, sua interlocução com as questões contemporâneas.

Dentre as questões que possibilitam o diálogo entre a Psicologia Analítica e a Psicologia, que visam à revitalização do modus faciendi dessa última, destaca-se, como campo fértil para reflexão, a discussão sobre as imagens psíquicas. Qual a importância do estudo da imagem ao longo do desenvolvimento da Psicologia? Qual a concepção da Psicologia Analítica sobre a imagem e suas contribuições para a Psicologia? De que modo a imagem pode favorecer uma reflexão no campo teórico? Como o estudo da imagem pode contribuir para a formação do psicólogo? De que modo a imagem vem sendo incorporada à prática clínica? 
Uma Contribuição para a Discussão sobre as Imagens Psíquicas no Contexto...

Embora ultrapassem os limites de um único trabalho, essas questões constituem um amplo campo de pesquisa e vão servir de base para esta reflexão.

O texto tem início com a discussão sobre a natureza da imagem e sua importância para a Psicologia e a para a psicoterapia. Na seqüência, discutese a hipótese da construção teórica por intermédio da imagem e as especificidades do aprendizado no campo das imagens. Por último, com vistas à interlocução com a realidade dos psicoterapeutas brasileiros, apresentam-se dados de estudo anterior (Sant’Anna, 2001), no qual se discutiu a inserção da imagem no contexto clínico.

Desse modo, pretende-se refletir sobre a evolução da questão da imagem na Psicologia Analítica - dos pontos de vista teórico-conceitual e da prática clínica -, em busca das contribuições que essa teoria pode oferecer para a Psicologia como um todo.

\section{Sobre a imagem psíquica}

Se a Psicologia tem como objeto estudar a psique ou o psiquismo, é preciso recuperar o significado subjacente à própria natureza do psíquico. A alma, como a Psicologia Analítica prefere denominar, é um fenômeno extremamente resistente a qualquer tipo de definição, uma vez fundada em leis que procedem muito mais da experiência e da manifestação do que do entendimento e do conceito. Em face das dificuldades que a Psicologia encontra para atingir e delimitar seu objeto, muitas propostas acabam por destituir a alma desse universo.

Em diferentes desenvolvimentos da Psicologia há uma tentativa de reduzir o psíquico ao comportamento, ao sintoma, ao símbolo, ao relacional, ao fisiológico, ao cognitivo, ao intrapsíquico, entre outros fenômenos, que, de fato, resultam dele e do qual são expressões parciais.

Para que a psique possa ser mais bem entendida, em lugar de provir de outros fenômenos, conviria observá-la a partir dela mesma, de sua própria 
ótica uma vez que ela é o único fenômeno imediato "percebido por nós e, por isso mesmo, a condição indispensável de toda experiência em relação ao mundo” (Jung, 1916/1986, p. 77).

Estudar a psique pela via do comportamento ou da cognição não seria o mesmo que estudar música servindo-se apenas da leitura de notas ou da análise das estruturas harmônicas em partituras, sem fazê-las soar num instrumento ou na voz? E para que seu objetivo fosse alcançado com mais precisão, não conviria que, ao estudá-la, a própria alma fosse refletida e evocada?

Consideráveis tendências da Psicologia moderna estão fundamentadas em pressupostos positivistas e em modelos de entendimento que, para compreendê-la, segmentam a experiência humana. É dessa fragmentação que inúmeros sistemas psicológicos procuram, cada um a seu modo, explicar e delimitar o psíquico. Dentre eles, há uma forte tendência que identifica a psique com o intelecto ou, mesmo admitindo seus componentes instintivos ou irracionais, trata-os - em lugar de sua própria dinâmica - da perspectiva e em função do intelecto, conferindo-lhes, portanto, uma conotação desviante ou patologizante.

O fenômeno psíquico não se revela pelo caminho do pensamento, do comportamento ou do sintoma, mas sobretudo por intermédio do fluxo de imagens - fonte desses pensamentos, comportamentos ou sintomas. Essa questão já inquietava os pioneiros da Psicologia científica.

As teorias sobre imaginação e imagens mentais exerceram papel considerável na história da Psicologia e Filosofia (p. ex., J. Locke, D. Hume, G. W. Leibniz, G. F. Herbart). Em alguns sistemas mais antigos, um conteúdo mental mais ou menos “perceptível” era caracterizado como imagem (idéia). Mais tarde, houve freqüentes tentativas, para fundamentar-se toda vida intelectual na imaginação e para serem reconhecidas as leis da associação e as regularidades das imagens mentais como princípios categoriais essenciais da inteligência. F. Galton foi o primeiro a estabelecer uma abordagem da investigação empírica sobre modos e funções da imaginação. (Arnold, Eysenck, \& Meili, 1982, p. 203)

Naquele contexto, a palavra imagem era empregada para designar uma representação mental mnemônica, elaborada sem as estimulações sensórias correspondentes, ou seja, uma representação consciente de objetos ou 
Uma Contribuição para a Discussão sobre as Imagens Psíquicas no Contexto...

de processos anteriormente percebidos pelos sentidos. Nesse caso, que entende a imagem apenas em relação aos processos perceptivos dos quais deriva, atribui-se a ela uma conotação secundária em face do papel que ela desempenha na psique.

Na concepção psicanalítica, além de representações mentais mnemônicas derivadas da percepção consciente, as imagens adquirem uma função dinâmica, uma vez que, para Freud, elas possibilitam a transferência da energia instintiva que não encontra seu objeto no campo da fantasia. "Os conteúdos das imagens mentais podem, mesmo sem intenção consciente da vontade, provocar o impulso à realização do que foi proposto em forma ideal ou imaginária” (Arnold et al., 1982, p. 204).

Para a Psicologia Analítica, a imagem não é apenas uma representação visual, resultado da percepção sensorial, da atividade mnemônica ou da transferência da energia psíquica, mas a linguagem básica da psique, criativa e autogeradora em si mesma. Assim, a imagem é também resultado da capacidade inerente da psique de agrupar elementos, de natureza perceptiva ou não, em gestalten - imagens primordiais -, que lhes atribuem forma, significado e dinamismo específicos. A imagem primordial é "um organismo de vida própria, 'dotado de força geradora', pois é uma organização herdada de energia psíquica, sistema sólido que não é somente expressão, mas também possibilidade de desencadear o processo energético” (Jung, 1921/1991, p. 422).

A mera percepção não é o fato que constitui o psíquico, do mesmo modo que o ato puro não passa de um sistema reflexo de ação e reação, ambos mais próprios à esfera biológica. No entanto, o que é percebido pelos sentidos - cheiro, gosto, textura, cor ou som -, ou as potencialidades instintivas inatas - arquétipos -, que se constelam ${ }^{3}$ no campo psíquico, fazem-no por meio de imagens.

A imagem interna é uma grandeza complexa que se compõe dos mais diversos materiais e da mais diversa procedência. Não é um conglomerado, mas um produto

3 O termo constelar é usado pela Psicologia Analítica para designar a ativação de um arquétipo. 
homogêneo, com sentido próprio e autônomo. A imagem é uma expressão concentrada da situação psíquica como um todo e não simplesmente ou sobretudo dos conteúdos inconscientes. É certamente expressão de conteúdos inconscientes, não de todos os conteúdos em geral, mas apenas dos momentaneamente constelados. Essa constelação é o resultado da atividade espontânea do inconsciente, por um lado, que sempre estimula a atividade dos materiais subliminares relevantes e inibe os irrelevantes. A imagem é, portanto, expressão da situação momentânea, tanto inconsciente quanto consciente. Não se pode, pois, interpretar seu sentido só a partir da consciência ou só do inconsciente, mas apenas a partir de sua relação recíproca. (Jung, 1921/1991, p. 418)

Ao refletir a natureza paradoxal da psique, a imagem apresenta-se à consciência de forma ambígua e multifacetada. Forma-se a partir da percepção como também da intuição, ou seja, os elementos que a compõem não podem ser reduzidos aos processos perceptivos, na medida em que também se originam da captação da realidade pela via do inconsciente. Nesse caso, a forma recebida pela imagem é concebida pela base arquetípica da psique. Contrariamente ao conceito, resultado do processo de depuração do pensamento racional, a imagem tem um componente ideativo associado a uma constelação emocional; é, ao mesmo tempo, uma idéia e uma emoção.

A imagem não se restringe ao aspecto visual, à imagem ou à representação de algo na consciência por meio de uma forma visualmente reconhecível ou representável. Tampouco é um fenômeno estático cuja forma se cristaliza numa configuração acabada. A imagem é um modo de percepção e captação de natureza fluida e dinâmica que se constitui no próprio ato da consciência.

Em outras palavras, a imagem é a consciência em seu estado puro; ocorre toda vez que a experiência do indivíduo encontra expressão na psique, seja pela via da percepção - visual, tátil, olfativa, gustativa ou auditiva -, seja pela da intuição, da emoção, da linguagem ou do sentido. Nesses casos, forma-se uma gestalt, que, embora inicialmente não possa ser apreendida racionalmente, pode ser reconhecida pela consciência, o que lhe possibilita a captação do experienciado.

Uma imagem pode permanecer em seu estado bruto, como uma forma direta de captação, assim como pode exercer na consciência um papel meta- 
Uma Contribuição para a Discussão sobre as Imagens Psíquicas no Contexto...

fórico, rico em conexões e possibilidades de sentido. Quando a imagem é ativada, a consciência se movimenta, articulando-se em busca de compreensão e de ampliação.

É por intermédio da imagem que a consciência pode se auto-observar em sua eterna constituição, em seu fluxo criativo. Sua expressão é fluida e dinâmica, uma vez que reflete o processo psíquico em seu desenvolvimento contínuo, em contraste com a tendência unilateralizante e cristalizadora do ego. Entretanto, se a imagem for depurada pela explicação racional, ela perde sua vitalidade, é dissecada e reduzida a idéias e conceitos estáticos e esquemáticos.

A imagem é a linguagem da expressão natural da psique, base de todos os processos psíquicos. Nesse sentido, ela tem coerência e validade em si mesma, sem necessidade de ser traduzida ou transposta para outros sistemas ou linguagens. Ela é a matéria-prima da psique, que pode ser trabalhada, cultivada, ativada, contemplada, mas não reduzida a explicações ou a conceitos.

\section{O trabalho com imagens no contexto clínico}

A investigação das imagens psíquicas é, portanto, de fundamental importância para a Psicologia, em geral, e para o seu objeto de estudo, em particular: a alma humana. Apesar disso, até a década de 1970, a Psicologia moderna ocupou-se muito pouco dessa questão.

Pope e Singer (1978) afirmam que a Psicologia tem "uma estranha relutância em reconhecer, em descrever, ou estudar seriamente essa sempre mutável constelação da memória, dos sentidos, antecipações, fantasias, pensamentos racionais e imagens que constituem nossa consciência de cada momento ao longo de nossas vidas” (p. 3).

Presentemente, questões referentes às imagens psíquicas, bem como às possibilidades de favorecimento de um cultivo das imagens na psicoterapia, vêm sendo cada vez mais discutidas. Pode-se mesmo dizer que todas as 
tendências terapêuticas atuais fazem uso, mais ou menos consciente, de uma abordagem clínica que inclui o trabalho com imagens. Das terapias behavioristas, que acreditam nas possibilidades transformadoras do poder de representação por meio de imagens - visualização -, às terapias que trabalham com a vivência e interpretação de sonhos, recorre-se às imagens como possibilidade de acesso e de intervenção nos processos psíquicos.

Dependendo da proposta terapêutica, como as de Desoille (1945), Leuner (1985) e Silveira (1982), que privilegiam exclusivamente a produção de imagens, bem como as que utilizam técnicas imagéticas como um recurso terapêutico, atribui-se mais ou menos importância ao fluxo das imagens.

Mc Mahon e Sheikh (1984) propõem a classificação das múltiplas abordagens da imagem em quatro categorias:

1. abordagens que se baseiam nos modelos de Pavlov e Skinner e tratam da relação entre imagens e reações emocionais e de seu uso como estímulos nos métodos de condicionamento;

2. abordagens que utilizam a produção de imagens como instrumento para aperfeiçoar a compreensão das distorções perceptivas e emocionais do paciente; contrariamente à categoria anterior, elas não trabalham com os princípios condicionantes;

3. abordagens que trabalham com pesquisas na área da saúde física e mental e que partem do pressuposto de que imagens "saudáveis” levam gradualmente a uma "realidade saudável”, sem, contudo, oferecerem interpretações ou teorias; e

4. abordagens que trabalham com técnicas profundas de produção de imagens - imaginação ativa, sonho guiado, jogo de areia (sandplay) etc. - e prognosticam a cura pela transformação psíquica, que se serve de processos irracionais em oposição às terapias racionais e reflexivas.

Nas diferentes abordagens, há sinais evidentes de um reconhecimento do valor adaptativo, criativo e terapêutico da produção de imagens psíquicas, em detrimento de um sentido regressivo, patológico ou perturbador, que a visão inicial da Psicologia lhe atribuía. Por isso, muda também a forma de abordar os produtos imagéticos no contexto clínico, que passa de uma atitu- 
Uma Contribuição para a Discussão sobre as Imagens Psíquicas no Contexto...

de interpretativa, reducionista e despotencializante para uma atitude nãointerpretativa, amplificadora e potencializadora. Em vez de uma orientação interpretativa, que visa à tradução ou à explicação das imagens, prioriza-se o estabelecimento de uma conexão emocional e vivencial com elas, provavelmente o modo mais eficaz de se aproximar da realidade psíquica do paciente.

Observa-se essa mesma tendência no desenvolvimento da Psicologia Analítica e de suas escolas. Samuels (1989) discute três direcionamentos teórico-práticos resultantes de ênfases em três aspectos teóricos - conceito de self, desenvolvimento do ego e conceito de arquétipo - e em três aspectos práticos - desenvolvimento do eixo ego-self, relação transferencial e diferenciação de imagens. Deles se originam a escola clássica, a desenvolvimentista e a arquetípica, respectivamente, que vão trabalhar com a imagem de modo diverso.

A escola clássica em Psicologia Analítica é a que se mantém mais próxima das idéias originais de Jung. Enfoca o conceito de self, sobretudo no que diz respeito à vivência do eixo ego-self, na segunda metade da vida. Destaca o caráter religioso dessa experiência, segundo o qual a consciência passa a se relacionar com uma dimensão transcendente, o si mesmo. Essa relação é mediada por imagens que assumem a função de símbolos, na medida em que buscam uma ponte entre consciente e inconsciente.

Nesse contexto, a imagem é vista como “mensageira” do self, o que a transforma numa concepção espiritualizante. Em termos práticos, o material imagético é tratado por meio da amplificação cultural, que busca explicitar seu caráter simbólico e universal. Embora Jung tenha questionado o método reducionista de interpretação da Psicanálise, as primeiras gerações de analistas junguianos manifestam um certo reducionismo da imagem ao símbolo (Hillman, 1977).

Em relação às técnicas, a escola clássica dá bastante atenção à imaginação ativa, ao trabalho com sonhos e às atividades expressivas. Por meio delas, Jung preconizava a realização de um diálogo direto e dinâmico com as imagens psíquicas que favorecesse a conscientização e a integração das dimensões inconscientes da psique e o estabelecimento do eixo ego-self. 
A escola desenvolvimentista emerge em decorrência da lacuna deixada pelo desenvolvimento da personalidade, nos primeiros anos de vida da escola clássica. Concentra-se, portanto, na identificação das etapas de desenvolvimento do ego a partir de padrões arquetípicos (Neumann, 1991, 1995) ou da desintegração e reintegração do self (Fordham, 1969). Essa escola aproxima-se muito da escola inglesa de Psicanálise, que, na psicoterapia, atribui um sentido especial à infância histórica e ao papel da regressão e da transferência.

Postula-se um modelo de desenvolvimento da consciência que parte de um estágio inicial de indiferenciação e identificação com o todo (self), seguido de um estágio de percepção imagética ou simbólica para chegar a um estágio de diferenciação e compreensão consciente, predominantemente egóica.

Na prática clínica, esse modelo reflete a indução a uma abordagem linear da imagem, ou seja, toda imagem é levada a passar por essas etapas para que seja integrada à consciência. Primeiramente, a imagem é sustentada sem nenhuma intervenção verbal até que se instale uma "regressão criativa”, que favoreça a constelação do self. Espera-se o desenvolvimento de uma série de imagens até o momento em que elas sinalizem a possibilidade de pontes com a consciência. Só então se inicia um trabalho interpretativo que visa a discriminar as etapas de desenvolvimento do processo do paciente, apoiado no conhecimento simbólico do terapeuta.

Nesse processo, ocorre uma tradução da imagem por meio de modelos de desenvolvimento, seja do mais primitivo ao mais desenvolvido, do instintivo ao espiritual, do mineral, animal ao humano, ou as etapas do processo alquímico. Faz parte desse processo, também, a compreensão da relação transferencial.

A escola desenvolvimentista abriu caminho para a análise de crianças, bem como para as abordagens corporais. Em relação às técnicas, observa-se o uso de atividades expressivas e lúdicas (Fordham, 1969), de amplificação cultural (Neumann, 1991, 1995), do jogo de areia (sandplay) (Kalff, 1981) e de técnicas corporais (Sandor, 1982). Busca-se, com elas, o desenvolvimen- 
Uma Contribuição para a Discussão sobre as Imagens Psíquicas no Contexto...

to da “consciência de ego", o que determina uma certa despotencialização e depuração da imagem em favor de uma compreensão racional.

A escola arquetípica, por sua vez, enfatiza os aspectos fenomenológicos da Psicologia Analítica, ao dar prioridade à observação dos fenômenos psíquicos em sua própria realidade existencial. Uma vez que a imagem é expressão direta da psique, ela assume papel central na reflexão e na prática clínica. Trabalhar no plano da imagem permite o reconhecimento dos movimentos da alma e sua integração à consciência.

Esse processo não se dá na transferência da imagem para um plano transcendente, simbólico ou espiritual, por meio da amplificação ou interpretação - abordagem simbólica -, mas mediante o desenvolvimento de uma consciência metafórica, apoiada em imagens que Hillman $(1977,1978)$ denomina "consciência de alma” - abordagem imagética.

As imagens não são vistas como representações, sinais, símbolos, alegorias ou comunicações, mas como fenômenos peculiares à psique. Propõese, portanto, um tratamento direto e vivencial da imagem, segundo o qual a explicação ou a interpretação egóicas são substituídas pela vivência, pelo tratamento lúdico e pela conexão emocional.

Enfatizam-se os aspectos funcionais e valorativos do arquétipo e não os formais e descritivos. Contrariamente à perspectiva simbólica, que tende a classificar as imagens em arquetípicas ou não a partir de sua forma - mais ou menos universais -, a perspectiva imagética da escola arquetípica propõe também a operacionalização desse conceito: o que torna uma imagem arquetípica é o modo como ela é tocada, não a forma dela.

Recorre-se ao sentido dado por Jung, segundo o qual os arquétipos são portadores de significado, razão pela qual o que determina o caráter arquetípico de uma imagem é sua capacidade de evocar significado, e não sua forma. Qualquer imagem pode tornar-se arquetípica, à medida que, ao ser trabalhada, passa a significar algo para o sujeito, revelando-se prenhe de emoção, de mistério e de sentido.

Em relação à prática clínica, prioriza-se a produção de imagens por meio de uma articulação poética da linguagem. Evocar imagens e permane- 
cer nelas, despertando seu valor arquetípico é, portanto, a base da abordagem imagética proposta por essa escola.

\section{A reflexão teórica pela via da imagem}

Construir uma teoria psicológica coerente com a realidade da psique foi uma das grandes preocupações de Jung. Na construção da teoria em Psicologia Analítica, sua preocupação voltou-se para teorias que possibilitassem um intercâmbio mais preciso de idéias, paralelamente a uma tentativa de se aproximar do fenômeno psíquico de modo não reducionista, em busca do respeito à sua natureza emocional e paradoxal.

Nos desenvolvimentos da Psicologia Analítica, verificam-se esforços por mais precisão conceitual - Fordham (1969), Neumann (1991, 1995), Whitmont (1990), entre outros -, bem como por aproximação fenomenológica do psíquico por meio das imagens - Berry (1974), Casey (1974), Corbin (1972), Hillman (1977, 1978, 1981, 1989), Moore (1993), Stein (1978), entre outros. Essas tendências são uma reflexão sobre as idéias de Jung a partir de pontos de vista diferentes.

A primeira vê conceitos que precisam ser delimitados e apreendidos racionalmente; a segunda, imagens que precisam ser evidenciadas e aproximadas vivencialmente. Há ainda uma outra tendência: a que destaca o papel simbólico das idéias de Jung - Jaffé (1989) e Edinger (1990).

Como toda ciência, a Psicologia necessita de teorias e conceitos que delimitem seu objeto de estudo e permitam o intercâmbio de informações entre pesquisadores. O modelo de ciência positivista, no entanto, que estabelece um distanciamento entre sujeito e objeto e a compreensão dos fenômenos sob uma ótica fragmentadora e reducionista, parece não refletir a natureza e a complexidade da alma. As diversas teorias psicológicas originam-se de visões parciais e alheias ao psíquico, imprimindo-lhe uma série de propriedades que não lhe pertencem. 
Uma Contribuição para a Discussão sobre as Imagens Psíquicas no Contexto...

Mais do que construir um conhecimento sobre a psique, cabe à Psicologia criar possibilidades de aproximação e relação com ela. Por isso, ela não pode permanecer somente no plano da reflexão teórica sobre o fenômeno psíquico; cabe-lhe, também, ser capaz de tocá-lo e refleti-lo. Para isso, a Psicologia necessita de paradigmas que favoreçam a aproximação efetiva da psique.

No século XX, a ciência deparou-se freqüentemente com a necessidade de reformular seus paradigmas, para que pudesse compreender de forma mais efetiva os paradoxos da natureza. A natureza deixa de ser um inimigo a ser vencido e dominado e passa a ser um parceiro com quem é preciso estabelecer uma relação de cooperação mútua. Em outras palavras, a natureza passa a ser ouvida e considerada em sua especificidade, reflexo de uma tendência que busca apreender e respeitar a linguagem própria dos fenômenos, em vez de decodificá-los e traduzi-los para um campo de referência alheio.

Por mudança de paradigma também vêm passando os mais recentes desenvolvimentos da psicoterapia, o que deverá trazer implicações profundas para a Psicologia do futuro (Capra, 1989; Le Shan, 1994).

No panorama da ciência contemporânea, as questões levantadas pela física quântica parecem ser de extrema importância para a construção de uma ciência da psique impregnada de realidade psíquica. Na Física moderna, a delimitação e a classificação dos fenômenos por meio de leis e conceitos fixos é substituída por uma visão mais fluida e dinâmica da realidade. Buscase identificar as tendências ou as probabilidades dos fenômenos, que são mais bem descritas por intermédio de padrões ou imagens subjacentes a elas.

Apesar da grande dificuldade de romper com os parâmetros eminentes da ciência positivista na sua época, ao entrar em contato com as idéias da Física quântica e com o pensamento oriental, Jung inicia um processo de formulação de uma nova perspectiva, que se vai consolidando ao longo de sua obra.

A crítica da ciência tradicional à obra de Jung enfatiza a imprecisão e a subjetividade de seus conceitos, o que, à luz da nova ciência, parece não ter conotação negativa. Os conceitos junguianos não são formulações fixas, 
mas tentativas sucessivas de descrição e de aproximação do psíquico. A falta de linearidade e clareza de raciocínio de Jung parece revelar uma tentativa constante de encontrar uma forma de falar sobre o psíquico, preservando sua natureza ambígua e paradoxal.

Jung usa, intensivamente, a amplificação como instrumento para a discussão de suas idéias, método que possibilita à reflexão permanecer aberta e ser reformulada e enriquecida sempre que necessário. Não há a preocupação com a precisão dos conceitos, mas com a complexidade da alma, que parece revelar-se de modo mais amplo, se abordada por intermédio da sobreposição de imagens.

Nesse método, percebe-se o reflexo de uma das idéias principais de Jung, o conceito de arquétipo e sua natureza paradoxal. O arquétipo é idéia, abstração mental, bem como emoção, comportamento ou instinto. Só há consciência psicológica, em sentido amplo, se ambas as dimensões se fizerem presentes, ou seja, se a idéia estiver integrada à emoção. Ao abordar os conceitos pelo caminho da amplificação, impregnando-os com a imprecisão e a fluidez características da alma, Jung parece buscar uma ponte entre a esfera mental e a emocional, conseqüentemente, uma aproximação mais integrada do fenômeno psíquico.

Em face dos impasses observados na reflexão teórica da Psicologia contemporânea, reconhecer as imagens subjacentes ou inerentes aos conceitos possibilitaria uma revitalização dela. Nesse caso, a teoria ganharia realidade psicológica, tornando-se uma esfera psiquicamente ativa.

Entretanto, sobre a possibilidade de construção de uma Psicologia pautada por imagens, a dicotomia entre imagem e conceito parece resistir, simultaneamente, à possibilidade de o conceito depurar a imagem psíquica de seu subjetivismo; ele distancia a reflexão e o entendimento da realidade psíquica, ressecando-o e desumanizando-o. Melhor do que construir uma teoria por imagens pode ser explorar melhor a imagem em seus aspectos funcionais como mediadora, mobilizadora e potencializadora dos processos psíquicos. 
Uma Contribuição para a Discussão sobre as Imagens Psíquicas no Contexto...

\section{Aprendizagem no campo de imagem}

Embora a questão da imagem esteja cada vez mais presente nas diversas abordagens, em Psicologia, sua ausência ainda é observada na formação dos psicólogos, seja do ponto de vista teórico (estudo da teoria da imagem), seja do prático (treinamento do psicólogo no campo das imagens). Os cursos de Psicologia não oferecem oportunidades para que o futuro psicólogo aprenda a articular sua compreensão e sua intervenção por meio de imagens ou recursos imagéticos.

A formação acadêmica prioriza o aprendizado conceitual por intermédio das várias teorias psicológicas. Nesse contexto, a imagem tem sido abordada de forma tangencial, uma vez que é encarada à luz de outros processos e não de sua própria natureza e especificidade fenomenológica. Acaba sendo reduzida aos processos perceptivos ou a um processo patológico.

Essa lacuna não permite que o profissional de Psicologia trabalhe adequadamente com sua matéria-prima: a psique. Ao olhar uma imagem de forma redutiva e interpretativa, ele interrompe e paralisa o processo psíquico e não favorece a potencialização do movimento auto-regulador da psique.

Uma das causas dessa situação não seria a dificuldade dos cursos acadêmicos de inserirem em sua grade curricular teorias que não estão alinhadas com uma visão positivista de homem? Nesse sentido, as abordagens que se abrem para os aspectos irracionais da psique e buscam um novo modelo de compreensão que os abarque acabam sendo vistas com desconfiança ou completamente omitidas da formação do psicólogo.

Embora permaneça quase ausente nos cursos de Psicologia, a Psicologia Analítica tem muito a contribuir para a discussão da questão da imagem, sobretudo com as reflexões realizadas pela escola arquetípica, que trata a psique como um processo vivo, razão pela qual o método para abordá-la deve refletir sua natureza. Em constante constituição, a imagem deve ser cultivada, ativada ou potencializada por meio de outras imagens que vão gerando um campo psíquico, mediante o qual é possível a relação em seus diversos níveis, intra e interpsíquicos. 
Os psicoterapeutas em atuação buscam preencher essa lacuna em sua formação, recorrendo a três situações: aprofundamento teórico, experiência vivencial da imagem e prática clínica (Sant’Anna, 2001).

No primeiro caso, a reflexão no âmbito teórico tem se dado em grupos de estudo ou em cursos de extensão, especialização ou formação, por meio de pesquisa sobre outras linguagens - verbal, corporal, artística e simbólica - e pela interlocução entre vertentes teóricas - fenomenologia, gestalt, psicossomática, arteterapia etc.

Em relação à segunda situação, observa-se a vivência de imagens no próprio processo analítico, em workshops e grupos de estudo, na experiência artística, em exercícios de imaginação com base corporal e em exercícios de amplificação e leitura simbólica de mitos, contos de fada etc.

Por último, a prática clínica em sua complexidade apresenta desafios que levam o terapeuta a buscar novos recursos de intervenção, que estão mais próximos da relação com a psique do que com a teorização sobre o psíquico.

Em face desse quadro, é pertinente discutir as possibilidades de ampliar, durante o processo de formação do psicólogo, o aprofundamento teórico e a aproximação vivencial da imagem. Pode-se pensar em situações de aprendizagem no contexto acadêmico e, paralelamente a ele, por meio de atividades de caráter teórico-prático ou vivenciais.

Em relação às primeiras, disciplinas como mitologia, estudo dos contos de fadas, história da arte, estudo da comunicação, arteterapia, estudo comparado das religiões, técnicas de mentalização e meditação, entre outras, poderiam fomentar a discussão sobre os fenômenos imagéticos.

O recurso à técnica de amplificação no estudo de casos clínicos, do simbolismo, dos produtos culturais ou dos fatos sociais e cotidianos, poderia promover o enriquecimento do repertório cultural e imagético do aluno, favorecendo sua compreensão da psique.

Pesquisas em busca da identificação da dinâmica e do comportamento de imagens expressas em pinturas, fotografias, filmes, desenhos, esculturas 
Uma Contribuição para a Discussão sobre as Imagens Psíquicas no Contexto...

ou em testes projetivos poderiam desenvolver habilidades para o trabalho imagético na clínica.

Nas supervisões clínicas, a reflexão e a compreensão poderiam partir de exercícios com imagens que ampliassem os referenciais sobre a situação estudada e levassem a uma aproximação afetiva entre o estagiário e seu cliente. E, no plano teórico, o estímulo à leitura dos teóricos da imagem, com imagens e por meio de imagens.

Em relação a uma abordagem vivencial da imagem, poderiam ser oferecidos grupos de vivências com imagens dos próprios alunos, que observariam, interagiriam e interviriam em processos imagéticos, com o cuidado, nesse caso, de que se crie um espaço continente e seguro para que aspectos da vida íntima deles possam ser abordados.

Outra possibilidade seria oferecer atividades de desenvolvimento da expressão por meio da linguagem artística, corporal, da imaginação ativa ou da meditação, a fim de despertarem a sensibilidade e possibilitarem a conscientização e a educação de outras formas de captação e articulação da compreensão, sobretudo a percepção intuitiva.

Assim como é impossível aprender a fazer pão sem pôr a mão na massa, no âmbito da imagem, a aproximação vivencial é inevitável. No entanto, essa aproximação tem de ser realizada com cuidado, levando em conta suas especificidades e seus riscos. No contexto acadêmico, o aprendizado da imagem por meio de uma abordagem vivencial apresenta certas limitações. Trata-se de uma experiência que deve ser muito bem estruturada, de modo que garanta a integridade psíquica do aluno, experiência nem sempre possível no contexto acadêmico tradicional, seja pela limitação dos objetivos do curso de graduação, seja pelas próprias limitações da estrutura acadêmica, que não garante o acompanhamento adequado desses processos.

É preciso também considerar que, em razão da faixa etária dos estudantes de Psicologia, é necessário privilegiar a função estruturante do curso universitário. Mesmo que ele favoreça abertura para perspectivas mais fluidas de pensamento, não se deve perder de vista a importância da estrutura- 
ção egóica por meio da atividade reflexiva, da aquisição de conceitos e da construção da persona profissional.

Fora do meio acadêmico, o aprendizado da imagem pode ocorrer em grupos de estudos e vivências com imagens presentes em sonhos, expressões artísticas, contos de fadas e mitos, mediante os quais é possível explorar os potenciais de desenvolvimento da imagem, bem como seus aspectos simbólicos ou teóricos.

Sem dúvida, o trabalho com as próprias imagens em terapia é a maneira mais ampla e profunda de treinamento no campo das imagens, uma vez que o psicólogo em formação pode estabelecer contato vivo e dinâmico com elas e adquirir compreensão psicológica sobre processos imagéticos.

\section{A inserção da imagem no contexto clínico, à luz da experiência de psicoterapeutas brasileiros}

A discussão sobre a questão da imagem manifesta-se, primeiramente, na reflexão teórica que a Psicologia vem realizando desde sua fundação até a atualidade e, posteriormente, na identificação de práticas clínicas que refletem a operacionalização e a constante atualização desses postulados. É importante identificar, portanto, na prática analítica, de que modo diferentes profissionais dialogam com as questões teóricas e as transformam em práticas clínicas efetivas. Como o conceito é validado, operacionalizado, enriquecido ou mesmo transformado na relação terapêutica.

Em estudo anterior (Sant'Anna, 2001), discutiram-se aspectos relativos à inserção da imagem na prática clínica, partindo dos aspectos teóricoconceituais para os de ordem prática. Realizaram-se entrevistas com seis psicoterapeutas de orientação junguiana, residentes na cidade de São Paulo, com o objetivo de verificar de que modo sua prática clínica poderia contribuir para essa discussão. Nelas, foram abordadas questões referentes à atitude do terapeuta, às técnicas utilizadas para trabalhar com imagens, à natureza da personalidade do paciente, às formas de abordagem da imagem e à função da imagem na psicoterapia. 
Uma Contribuição para a Discussão sobre as Imagens Psíquicas no Contexto...

\subsection{Uma reflexão sobre os resultados da pesquisa.}

Em relação à atitude do terapeuta, o trabalho com imagens revelou-se fruto da sua atitude imaginativa, dependendo, portanto, de sua fluência imagética e de sua capacidade de caminhar na incerteza e na inconstância desse processo. Ao trazer para a discussão analítica as imagens, mediante as quais ele capta a realidade do paciente, o terapeuta abre um campo de compreensão pelo caminho da imagem. Mas se ele não detiver essa habilidade, o trabalho com imagens torna-se difícil.

A atitude do terapeuta pode favorecer, portanto, a criação de um setting analítico fluido, e no qual a imagem se manifesta como campo de interação entre sua própria realidade e a realidade do paciente. O foco está no encontro e na relação entre duas psiques, cuja apreensão e mediação podem aflorar por intermédio das imagens que irrompem nesse contexto. À medida que as imagens, do terapeuta e do paciente, se manifestam, cria-se uma atmosfera psíquica favorável para o relacionamento terapêutico centrado na fluência da psique.

Se o terapeuta não estiver preocupado em fomentar a relação transferencial e tomar os sintomas da transferência e contratransferência como imagens que servem de indicadores da relação terapêutica, não se estabelece uma relação de dependência, razão pela qual o paciente fica à mercê do saber do analista; ele aprende a considerar suas imagens internas como referenciais de seu processo.

Ao trabalhar com imagens, como forma de captação e elaboração da situação psíquica do paciente, a atitude do terapeuta deve pautar-se mais pela intuição do que pela técnica. A intuição é uma abertura para o que é percebido pelo caminho do inconsciente sem o controle e a lógica do ego. É uma forma de captação irracional, que pode ser paralisada e ofuscada, na medida em que o terapeuta se apóia mais na técnica do que na observação de sua ocorrência.

É preciso considerar, no trabalho com imagens, que o que se manifesta na imagem está diretamente ligado à importância e ao enfoque que o tera- 
peuta dá a ela. Se o terapeuta não vê nada na imagem, não pode levar o paciente a fazê-lo; se ele busca encaixar as imagens nos modelos de desenvolvimento imagético que conhece, vai reduzi-las a esses modelos; mas se ele enxerga na imagem um processo vivo em andamento, vai potencializar esse processo.

Todo enfoque dado à imagem pelo terapeuta é, de certa forma, um tipo de interpretação. Entretanto, dependendo da situação, ele pode fomentar uma atitude mais ou menos interpretativa. No primeiro caso, prioriza a compreensão e a atribuição de sentido a uma imagem; no segundo, prioriza a vivência e a ativação do potencial mobilizador e mediador da imagem.

A formulação pelo caminho das imagens pode também ser favorecida pelo modo como o terapeuta organiza seu discurso. Se o discurso analítico for apoiado na atividade reflexiva e racional, em busca de referências na teoria e na organização lógica dos fatos, a produção de imagens não é estimulada como possibilidade de compreensão. Se, no entanto, o discurso for permeado pela atividade associativa, criando metáforas que servem como indicadores e potencializadores de uma situação, a função mediadora das imagens é ativada e, sua fluência, favorecida.

Em relação às técnicas utilizadas para trabalhar com imagens, em psicoterapia de orientação junguiana, destacam-se a imaginação ativa, o trabalho com sonhos, os recursos expressivos, o trabalho de base corporal, o contato com imagens artísticas ou míticas e a própria relação terapêutica.

A imaginação ativa pode ser utilizada de modo mais puro, como descrito por Jung, ou em conjunto com outras técnicas ou instrumentos. Observa-se acentuada dificuldade de realizá-la em sua forma original, uma vez que é muito reduzido o número de pessoas que consegue entrar na imaginação ativa. Por isso, o recurso a ela, na prática clínica, é bastante limitado. Se, no entanto, ela for associada a outros recursos que facilitem a expressão e a objetivação da imagem, ela ganha crescente espaço na psicoterapia. Por intermédio da interação com desenhos, pinturas, escrita espontânea, jogo de areia e exercícios corporais de imaginação, é possível desenvolver um diálogo dinâmico com as imagens e, ao mesmo tempo, observar seu desenvolvi- 
Uma Contribuição para a Discussão sobre as Imagens Psíquicas no Contexto...

mento. Uma contribuição original nessa área é o conceito de imaginação corpo-ativa (Gallbach, 1997), que consiste na realização da imaginação ativa integrada à experiência corporal.

O sonho, por sua vez, tão comum à experiência de qualquer pessoa, é um fenômeno que pode se prestar, com mais facilidade, a uma abertura para o trabalho com imagens. Por intermédio das imagens oníricas, é possível levar o indivíduo a estabelecer uma relação com processos em desenvolvimento na sua psique, bem como a manter o foco da terapia na esfera da alma. Tradicionalmente, a Psicologia Analítica trabalha com sonhos no contexto psicoterápico individual.

Nos últimos vinte anos, sob influência de técnicas utilizadas por outras abordagens, como a gestalt, vêm se desenvolvendo trabalhos com sonhos em grupos. Trata-se de um trabalho predominantemente vivencial, que busca a aproximação direta com o sonho, mediante o qual o grupo funciona como mediador e amplificador da imagem. Para que o sonho possa ser trabalhado em grupo, é necessário garantir um contexto grupal seguro, que possibilite intimidade, sigilo e calor humano entre seus componentes.

Ao trabalhar com sonhos, é importante o registro deles para que o terapeuta tenha um referencial do processo do paciente. Por meio do desenvolvimento das imagens ao longo de uma série onírica, é possível identificar aspectos que estão sendo ativados no inconsciente, conflitos ou novas sínteses que estão sendo formuladas, entre outros.

Em relação aos recursos expressivos - desenho, pintura, escrita espontânea ou jogo de areia (sandplay) -, eles podem ser utilizados dentro ou fora do setting analítico como catalisadores de imagens. Por intermédio desses recursos, é possível objetivar a imagem e dialogar com ela, bem como despontencializá-la em momentos de intensa atividade psíquica. No entanto, é fundamental que se estabeleça uma ponte entre o inconsciente e a consciência, sem a qual esse trabalho perde sua eficácia terapêutica. Assim como o trabalho com sonhos, o registro das imagens também é importante para o terapeuta como referencial do processo do paciente. 
A respeito do trabalho de base corporal, ele pode ser desenvolvido em dois sentidos: no primeiro, para identificar uma imagem no sintoma ou na manifestação orgânica de uma doença, que sirva de ponte para seus aspectos psíquicos; no segundo, para estimular o fluxo de imagem por meio de técnicas corporais. Nesse caso, é importante que o terapeuta tenha consciência do risco que pode representar para o paciente a ativação do fluxo imagético pelo caminho do corpo. Se esse tipo de trabalho vier a romper as defesas profundas registradas no corpo, pode desencadear-se uma invasão do inconsciente e a desestruturação da personalidade do paciente.

No Brasil, a abordagem corporal aparece como uma tendência marcante entre os terapeutas junguianos que receberam influência das idéias de Sandor (1982).

Outro modo de desencadear o processo associativo e o fluxo imagético, bem como de dar forma e conter imagens que afloram de modo intenso e fragmentado na consciência, é oferecer ao paciente imagens de obras-de-arte ou de mitos.

No primeiro caso, em que há um bloqueio que impede o sujeito de produzir imagens, entrar em contato com imagens externas pode favorecer conexões que estimulem o fluxo imagético; no segundo, as imagens universais dos mitos e da arte podem ajudar o indivíduo a dar forma e unidade para as imagens que se apresentam à consciência, aparentemente sem nenhuma conexão ou sentido. Assim como o arqueólogo, que recorre à forma de um vaso, buscando sentido e unidade para os fragmentos de um vaso real, o psicólogo pode recorrer às imagens universais como referência dos processos psíquicos.

Apesar dos recursos e das técnicas, o trabalho com imagens é, sobretudo, uma construção dialética, realizada no confronto direto com a imagem, razão pela qual ele não pode ser delimitado àquelas; seu recurso é a própria relação terapêutica, que pode favorecer ou não a captação pelo caminho das imagens.

Nessa relação, é preciso considerar a natureza da personalidade do paciente e suas implicações para o trabalho clínico com imagens. Observa-se 
Uma Contribuição para a Discussão sobre as Imagens Psíquicas no Contexto...

que, ao trabalhar com imagens, deve-se respeitar a natureza do indivíduo e suas resistências em entrar no campo imagético. Os recursos utilizados nunca devem tentar romper essas defesas, uma vez que isso pode resultar numa desestruturação do ego. Se as resistências forem muitas, cabe ao terapeuta manter as imagens como referências, e não forçá-las na relação com o paciente.

Em função da estrutura de ego do paciente, é possível adotar uma atitude mais ou menos interpretativa. Se o ego é pouco estruturado, como é o caso de indivíduos com uma organização psicótica de personalidade, o trabalho deve favorecer uma estruturação do ego. Nesse caso, uma atitude mais interpretativa pode oferecer o senso de orientação necessário para a concretização desse processo. Se o ego se encontra enrijecido pela impermeabilidade da organização neurótica, uma postura mais fluida e menos interpretativa pode favorecer a flexibilização e o enriquecimento do ego, graças à integração de outras perspectivas provenientes do inconsciente.

As imagens que emergem no contexto da psicoterapia podem ser abordadas por meio da amplificação no grupo, da interpretação, da abordagem simbólica e da abordagem imagética.

A amplificação é um recurso que torna presente e enriquece a imagem por meio do processo associativo e pode ocorrer em dois planos: na esfera pessoal e na esfera coletiva. Entretanto, no contexto clínico, a amplificação deve permanecer na esfera pessoal, porque, desse modo, é possível levar o paciente a estabelecer uma relação mais próxima com suas imagens.

Na esfera coletiva, por sua vez, a amplificação pode levar à inflação do ego, o que é prejudicial e indesejável para a terapia, razão pela qual ela só deve ser usada em última hipótese e com o objetivo de desencadear o processo associativo.

Um terapeuta que estimula, freqüentemente, a amplificação arquetípica pode estar num estado de inflação, tentando, inconscientemente, passar uma imagem supervalorizada de si e do seu papel na terapia. Resultado: ocorre um distanciamento da realidade psíquica do paciente e uma polarização do conhecimento do terapeuta. Fora da situação clínica, a amplificação pode ser um instrumento importante para o estudo de casos, uma vez que ele 
permite ao terapeuta encontrar referenciais sobre o material clínico e o desenvolvimento psíquico do paciente.

A amplificação, no contexto grupal, ocorre quando a imagem é enriquecida pelos diversos enfoques que os diferentes elementos do grupo atribuem a uma imagem. Seja por meio de perguntas que visam a recuperar a imagem e explorar as associações que o sujeito faz com elas, seja por meio da troca de impressões ou sobreposição de imagens, oportunidade em que se amplifica a imagem inicial até que se obtenha uma resposta pessoal em relação a ela.

No outro extremo, a interpretação é uma forma de aproximação da imagem, mediada por uma teoria ou por uma referência externa à própria imagem. Sempre que se atribui sentido à imagem ocorre interpretação, contudo, é possível estabelecer relações mais ou menos abertas. A interpretação tende a reduzir a imagem a uma idéia, a um conceito, a um símbolo ou a uma ocorrência da vida do sujeito, o que pode despontencializar sua função mobilizadora e mediadora. Portanto, numa interpretação, é importante respeitar a natureza multifacetada e polissêmica da imagem, levando em consideração todos os seus aspectos.

Na Psicologia Analítica, observa-se a predominância de duas abordagens da imagem: a simbólica e a imagética. A abordagem simbólica evidencia os símbolos presentes nas imagens ou nas situações de vida do sujeito e busca neles as referências que possibilitem sua aproximação. Nesse caso, a relação com a imagem é mediada pelo símbolo, o que exige certo cuidado por parte do terapeuta, para que não ocorra uma redução da imagem ao símbolo.

A abordagem imagética ou não-interpretativa é a aproximação direta da imagem e a ativação de sua função mediadora; ela vê na imagem uma forma de comunicação válida em si, que precisa ser conectada e não traduzida ou interpretada. Nesse caso, busca-se mobilizar a imagem no que ela oferece como referencial, ao invés de entendê-la por meio de elementos que não lhe pertencem. Uma vez ativada, a imagem serve como interface para as várias situações vividas pelo indivíduo, com as quais ele pode estabelecer relações, mediante as diferentes perspectivas oferecidas. 
Uma Contribuição para a Discussão sobre as Imagens Psíquicas no Contexto...

A função da imagem, no contexto clínico, pode ser curativa, ampliadora de consciência, mediadora, indicadora de processo, potencializadora e mobilizadora. A imagem pode promover cura, à medida que oferece uma visão totalizadora da experiência do indivíduo. Cura não é só consciência e compreensão; ela envolve também emoção e todos os aspectos da personalidade da pessoa. Nesse sentido, a imagem possibilita, simultaneamente, uma percepção cognitiva e emocional, integrando assim essas duas modalidades de captação da experiência.

A imagem promove a ampliação da consciência, à medida que amplia os referenciais do ego. Em decorrência do caráter polissêmico e polivalente, que lhe é próprio, apresenta múltiplas visões sobre as situações vividas pelo sujeito e o leva a uma perspectiva consciente mais abrangente. Ao favorecer a relação e o diálogo entre as esferas consciente e inconsciente, entre mundo interior e mundo exterior, exerce neles uma função mediadora.

A observação do fluxo imagético e de seus desdobramentos favorece ao terapeuta e ao paciente perceberem os movimentos realizados, os pontos de estagnação e os aspectos em potencial, ao longo da psicoterapia.

Além de sinalizar, a imagem pode também mobilizar e potencializar aspectos da personalidade do sujeito, à proporção que possibilita à consciência ativar outros potenciais de ação e compreensão ainda latentes no inconsciente.

\subsection{Considerações finais}

Observa-se na discussão sobre a inserção da imagem na prática clínica realizada pelos entrevistados que, apesar das referências às formas clássicas de trabalho com imagens, ou seja, à amplificação, à imaginação ativa e ao trabalho com sonhos, apenas este parece ser utilizado com mais freqüência.

A amplificação parece ser mais usada como referência ou como método de análise de estudo de casos e de fenômenos socioculturais. A imaginação ativa, na sua forma mais pura, é pouco empregada em razão do grau de dificuldade que apresenta. E o trabalho com sonhos, referido por todos os entrevistados, parece manter-se como o eixo da atividade terapêutica de base 
junguiana. Nesse caso, foi observada uma ampliação dessa prática com a proposta de trabalho com sonhos em grupos.

A forma de a imagem ser inserida na prática clínica parece estar mais ligada à situação específica com a qual o terapeuta se depara do que às técnicas ou posturas teóricas específicas. Nesse contexto, os conceitos e as técnicas servem como referência e não como norma da prática clínica. O enfoque dado à ação terapêutica passa, portanto, pela relação dialética entre terapeuta e paciente.

Embora tenham ocorrido várias referências à abordagem simbólica, é expressivo o movimento em direção a uma abordagem fenomenológica e não-interpretativa da imagem. É considerável a preocupação de encontrar outras formas que favoreçam o diálogo direto com imagens, dentre as quais, a proposta de imaginação corpo-ativa e o trabalho de imaginação por meio de recursos expressivos ou artísticos - contos de fadas e jogo de areia.

Outro ponto de destaque na discussão sobre a inserção da imagem na prática clínica é a unanimidade dos entrevistados em relação à necessidade de interação consciente com as imagens.

Foram constantes e expressivas as críticas aos trabalhos que promovem a expressão ou o desenvolvimento da fluência imagética, sem a preocupação de integrá-la à consciência. As imagens, por si sós, sem relação com a consciência e a vida imediata do indivíduo, não têm valor terapêutico. De modo que, para que não se corra o risco de perder a conexão com a realidade e se favoreça um estado de alienação, é necessário que se façam pontes com a situação consciente do indivíduo.

Ocorreram também críticas às leituras essencialmente simbólicas, que polarizam o processo terapêutico numa esfera muito espiritualizada, em detrimento da dimensão instintiva e da conexão com a experiência imediata do indivíduo. São sinais de um deslocamento da postura inicial da Psicologia Analítica em direção a uma atitude terapêutica que favoreça o cultivo da alma como campo intermediário entre espírito e instinto. Esse movimento sugere a influência da escola arquetípica. 
Uma Contribuição para a Discussão sobre as Imagens Psíquicas no Contexto...

Paralelamente, as técnicas de base corporal apóiam-se amplamente nas idéias de Neumann, sobretudo na noção de consciência matriarcal, de caráter unitário e emocional, segundo a qual corpo e psique fazem parte de uma mesma unidade. O processo de conscientização e de cura inicia-se sempre nessa dimensão, com a constelação do self evoluindo para a dimensão espiritual da consciência patriarcal.

Nas referências dos entrevistados, a noção de cura é redimensionada à luz da perspectiva holística e integradora e definida como o restabelecimento do equilíbrio e a integração entre os múltiplos aspectos da experiência do indivíduo. Rejeita-se, portanto, o modelo médico que dicotomiza a doença e a saúde.

A ampliação de consciência perde importância, se ela representar uma ampliação unilateral do ego, ao invés do estabelecimento de um diálogo ativo e criativo entre as várias esferas da psique. Destaca-se, portanto, como objetivo central da psicoterapia, promover o relacionamento inter e intrapsíquico. As palavras mais usadas pelos entrevistados para descrever esse processo foram: conexão, relação, relacionamento, ponte, integração, diálogo, comunicação, interação e mediação.

Para finalizar, é importante pontuar que fazer um recorte da Psicologia Analítica, mediante a análise do desenvolvimento do conceito de imagem, possibilita verificar o valor teórico-operacional desse conceito, bem como sua relevância para todos os seus desenvolvimentos. A discussão que vem sendo feita a respeito da imagem e de seu potencial clínico é extremamente dinâmica e reverbera na prática clínica e reflexiva dos psicoterapeutas da atualidade.

Sant'Anna, P. A. (2005). A contribution to the discussion about psychic images in the analytical psychology context. Psicologia USP, 16 (3), $15-44$.

Abstract: The discussion about the nature of psychic images has been present since the beginning of psychology. In the last decades this subject 


\section{Paulo Afrânio Sant’Anna}

has been highlighted in all approaches, reflecting in clinical modalities that are predominantly based on the imagistic speech. To the Analytical Psychology, the issue of image has been the focus of many discussions and among them three theoretical-practical tendencies are emphasized classic, developmental and archetypical - that determine different perspectives on that issue. It is observed a tendency of treating the image in its own phenomenology instead of its interpretation and in spite of the importance of the images to the clinical context, this subject is nearly absent in psychology graduation programs and in the theorization process. In this sense, some proposals are discussed as possibilities of learning and theorization in the field of image.As the dialectic relation between theory and practice is needed in order to the upgrading of the theory and its vital connection to the contemporary social-cultural reality, through data obtained from interviews with Brazilian psychotherapists, contributions for the discussion about images on the clinical context were identified.

Index terms: Imagery. Psychotherapy. Junguian psychology. Psychologist education.

Sant'Anna, P. A. (2005). Une contribution pour la discussion sur les images psychiques dans le context de la Psychologie Analytique. Psicologia USP, 16 (3), 15-44.

Résumé : La discussion sur la nature des images psychiques est présent depuis le début de la Psicologie. Dans les dernières décades le théme a été mise en évidence par toutes les modalités cliniques qui s'appuient principalement dans le discours imagetique. Pour la Psicologie analytique la question de l'image est l'objet de plusieurs discussions et parmis elles il y a trois tendences théoriques et pratiques - classique, developpmentiste et archétypique - qui iront déterminer differentes perspectives sur la question. On peut observer une tendance pour approcher l'image d'aprés sa propre phenomenologie au détriment de son interpretation. Malgré son importance pour le contexte clinique, le theme est pratiquement absente des programmes de baccalauréat/1e. Cycle en Psychologie et de la structuration des theories psychologiques. Dans ce sens quelques propositions sont discutés comme possibilités d'apprentissage et de theorization dans le champ de l'image. Comme la relation dialectique entre la théorie et la pratique est nécessaire pour que la théorie reste actuelle et vivement liée a la realité socio-culturelle contemporaine, utilisant des données obtennues en 
Uma Contribuição para a Discussão sobre as Imagens Psíquicas no Contexto...

interviews avec psychothérapeutes brèsiliens, on a cherché a identifier contribuitions pour la discussion sur l'images dans le context clinique

Mots-clés: Image. Psychothérapie. Psychologie jungienne. Formation du psychologue.

\section{Referências}

Arnold, W., Eysenck, H. J., \& Meili, R. (Coords.). (1982). Dicionário de psicologia (Vol. 2). São Paulo: Loyola.

Berry, P. (1974). An approach to dreams. Spring, 58-79.

Capra, F. (1989). O ponto de mutação. São Paulo: Cultrix.

Casey, E. S. (1974). Toward an archetypal imagination. Spring, 1-32.

Corbin, H. (1972). Mundus imaginalis or the imagery and the imaginal. Spring, 1-19.

Desoille, R. (1945). Le rêve eveillé en psychothérapie: essaie sur la fonction de regulation de l'iconscient collectif. Paris: P.O.F.

Edinger, E. F. (1990). Anatomia da psique: o simbolismo alquímico na terapia. São Paulo: Cultrix.

Fordham, M. (1969). Children as individuals. London: Hodder \& Stoughton.

Gallbach, M. R. (1997). Grupo de vivências de sonhos: uma investigação sobre formas de trabalho com sonhos. Tese de doutorado, Instituto de Psicologia, Universidade de São Paulo. São Paulo.

Hillman, J. (1977). An inquiry into image. Spring. York, 62-88.

Hillman, J. (1978). Further notes on image. Spring. 152-182.

Hillman, J. (1981). Estudos de psicologia arquetípica. Rio de Janeiro: Achiamé.

Hillman, J. (1989). A blue fire: selected writings. New York: Harper Perennial.

Jaffé, A. (1989). O mito do significado na obra de Jung. São Paulo: Cultrix.

Jung, C. G. (1986). A natureza da psique. Petrópolis, RJ: Vozes. (Trabalho original publicado em 1916)

Jung, C. G. (1991). Tipos psicológicos. Petrópolis, RJ: Vozes. (Trabalho original publicado em 1921) 


\section{Paulo Afrânio Sant’Anna}

Kalff, D. M. (1981). A psychotherapeutic approach to psyche (2a ed.). Boston: Sigo Press.

Leuner, H. (1985). Lehrbuch des katathymen bilderlebens. Huber: Bern.

Le Shan, L. (1994). O dilema da psicología: o olhar de um psicólogo sobre sua complicada profissão. São Paulo: Summus.

Mc Mahon, C. E., \& Sheikh, A. (1984). A imagination in disease and healing processes: a historical perspective. In A. A. Sheikh (Ed.), Imagination and healing (pp. 7-33). Formingdale, New York: Baywood.

Moore, T. (1993). Cuide de sua alma. São Paulo: Siciliano.

Neumann, E. (1991). A criança: estrutura dinâmica da personalidade em desenvolvimento desde o início de sua formação. São Paulo: Cultrix.

Neumann, E. (1995). História da origem da consciência. São Paulo: Cultrix.

Pope, K. S., \& Singer, J. L. (1978). The use of imagery and fantasy techniques in psychotherapy. In L. S. Jerome \& S. P. Kenneth (Ed.), The power of human imagination: new methods in psychotherapy (pp. 3-34). New York: Plenum Press.

Rhyne, J. (1973). The gestalt art experience. Belmont,CA: Wadsworth.

Sandor, P. (Org.). (1982). Técnicas de relaxamento. (4a ed.). São Paulo: Vetor.

Sant'Anna, P. A. (2001). As imagens no contexto clínico de abordagem junguiana: uma interlocução entre teoria e prática. Tese de doutorado, Instituto de Psicologia, Universidade de São Paulo, São Paulo.

Samuels, A. (1989). Jung e os Pós-junguianos. Rio de Janeiro: Imago.

Silveira, N. (1982). Imagens do inconsciente (2a ed.). Rio de Janeiro: Alhambra.

Schwartz, G. (1973). Biofeedback as therapy: some theoretical and practical issues. American Psychologist, 28, 666-673.

Stein, R. (1978). Incesto e amor humano - a traição da alma na psicoterapia. São Paulo: Símbolo.

Whitmont, E. C. (1990). A busca do símbolo. São Paulo: Cultrix.

Recebido em: 8.12.2004

Revisto em: 3.06.2005

Aceito em: 20.08.2005 